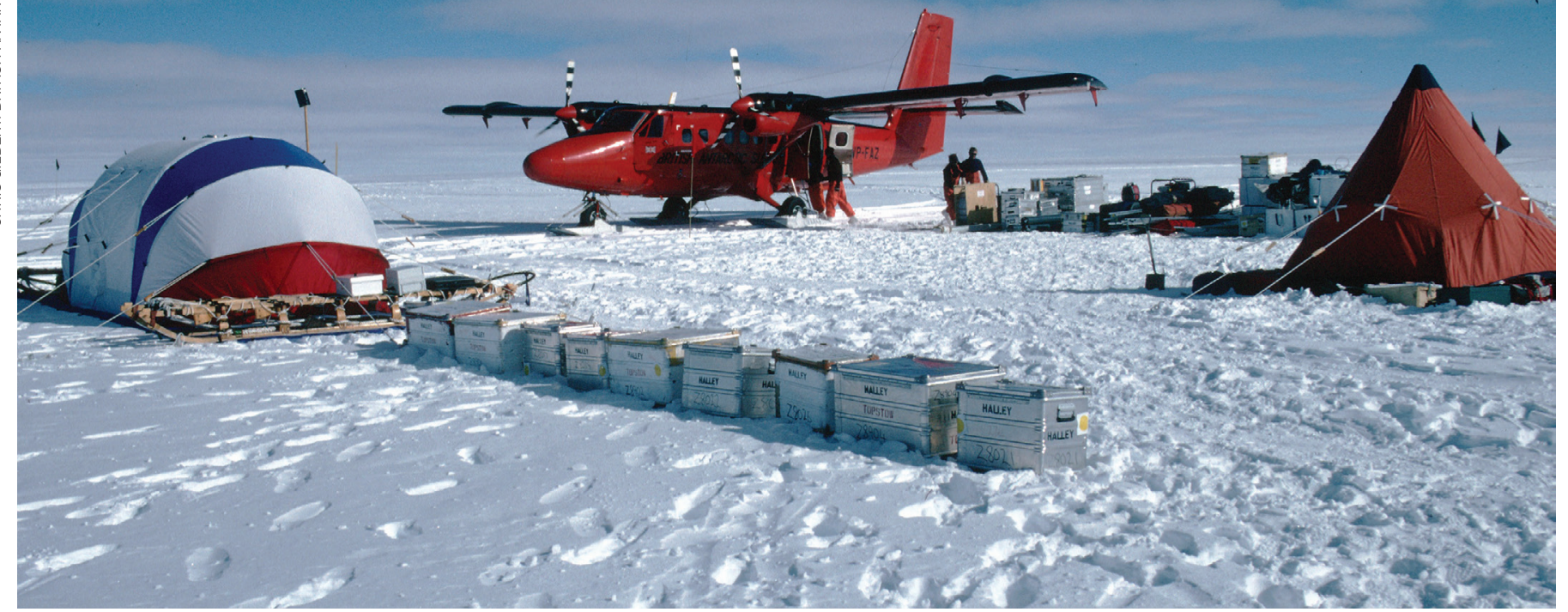

Geoscientists will drill for a 2.75-kilometre ice core in East Antarctica.

and greenhouse-gas history of the past 800,000 years. The cores showed that, over this time, there were 8 pronounced glacial cycles that each lasted nearly 100,000 years.

The new core will extend the record to a period when the pattern of climate variability was markedly different.

Marine sediments suggest that, before about one million years ago, the climate oscillated in 40,000-year cycles. Barbante says that a 1.5-million-year-old ice core will provide clues to what caused the transition - a major question in the Earth and climate sciences.

Barbante thinks that it will take four years to complete the mechanical drilling. The team will begin its mission next year, by lowering a tube with a cutting head into a casing inserted in the topmost 100 metres of ice. A drilling liquid will prevent the borehole from closing.

\section{A SECOND OPINION}

Proper drilling into the ice sheet will proceed in the 2020-21 Antarctic field season. Icedeposition models and exploration at the site, including several reconnaissance drills and radar measurements taken from the air, suggest that the oldest ice at the bottom of the sheet is undisturbed by melting or folding.

"We're very confident that the bottommost 300 metres have the missing climate information that we want to find," says Barbante.

The French-Italian Concordia Station, about 40 kilometres northeast of the drilling site, will provide logistical and medical support throughout the five-year project.
Meanwhile, Australian researchers are looking for an appropriate site at which to drill for a separate deep ice core nearby. A team hopes to establish camp on little Dome C in January 2021. With logistical support from Concordia Station, drilling could start later that year, or in 2022.

"We don't see it as a race or competition," says Tas van Ommen, a glaciologist with the Australian Antarctic Division in Hobart, who leads the Aus\$50-million (US\$36-million) project. "There's plenty of room for friendly cooperation."

A second core would be extremely desirable for replication purposes, says Barbante. "Two is better than one," he says. "You can never be confident in a single record. And, who knows, just a few kilometres apart might tell a completely different story."

\title{
Canada budget overlooks research
}

\section{Basic science gets only small spending bumps, unlike last year.}

\section{BY BRIAN OWENS}

$\mathrm{W}$

hat a difference a year makes. Canada's 2019 budget, released on 19 March, includes modest increases for Prime Minister Justin Trudeau's government priorities, including neuroscience and genomics research - nothing like the historic five-year,
Can \$4-billion (US\$3-billion) boost for basic science and research unveiled in 2018. The 2019 funding plan also proposes creating an advisory body that would subject future government funding decisions for research to greater scientific scrutiny.

The latest budget does not include new money for basic science projects at Canada's three main research-grant agencies because of the funding boost they received last year. And it contains only modest amounts - Can $\$ 459$ million over the next five years - for specific scientific organizations and institutions.

This spending plan is the last to be released before the federal election in October. As such, many researchers expected it to include funding for government priorities that would play well in the upcoming campaign, such as cancer research. Many institutions and organizations lobbied for a piece of the budget, breaking the united front that the science community presented last year when it demanded that the government follow the recommendations of the Fundamental Science Review - an independent assessment of Canada's research priorities and funding. The review recommended boosting spending on basic research from Can $\$ 3.5$ billion 


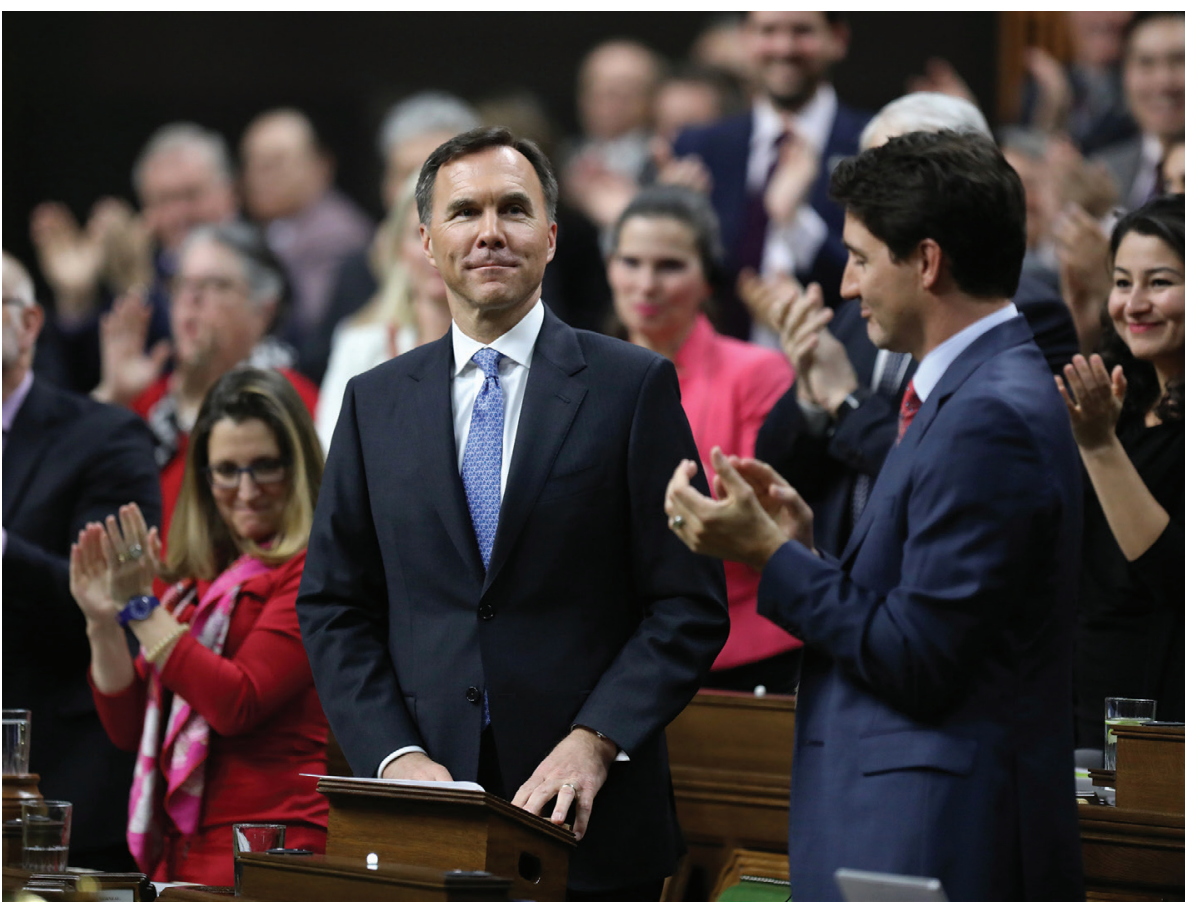

Prime Minister Justin Trudeau (right) and Canada's finance minister deliver the budget to Parliament.

- per year to Can $\$ 4.8$ billion.

The Stem Cell Network, a non-profit organization in Ottawa that helps to translate research into clinical applications, will receive Can $\$ 18$ million over three years, as part of the 2019 budget. Two cancer charities will receive a combined Can $\$ 160$ million; Genome Canada, a non-profit organization in Ottawa that supports genomic research, will get about Can $\$ 100$ million over five years; and the TRIUMF physics research lab and cyclotron in Vancouver will get Can $\$ 196$ million over five years.

But for basic science funded by competitive peer-reviewed grants, this is a disappointing budget, says Jim Woodgett, director of research at the University of Toronto's LunenfeldTanenbaum Research Institute. Such a selective approach to funding abandons the Fundamental Science Review plan, he adds. "Science thrives with open grant competition. It is asphyxiated by picking winners."

The budget does include a promise to stop awarding funding on the basis of lobbying or political calculation. The government proposes setting up the Strategic Science Fund, which will "operate using a principles-based framework for allocating federal funding that includes competitive, transparent processes". An independent panel of experts will use the framework to choose recipient organizations, and determine how much money they will get, in a competitive allocation process. The fund would begin operating in 2022.

This would be a big step towards improving how government money is allocated for science, says Katie Gibbs, executive director of the science campaign group Evidence for Democracy in Ottawa. "There are a lot of different thirdparty organizations that get funding directly from the budget, and this is a step to hopefully increase transparency and accountability in how they are chosen and funded."

The budget is also moving in the right direction for science students. The government's plan allocates Can $\$ 114$ million over five years to increase the number of graduate scholarships available from the country's three main research-funding agencies. The money will provide an additional 500 master's scholarships and 167 doctoral scholarships per year. The lack of support for students in last year's otherwise positive budget had been considered a "glaring omission", says Gibbs.

Tina Gruosso, co-president of Science and Policy Exchange, an advocacy group in Montreal run by graduate students and postdoctoral fellows, says students are happy with the support for scholarships. "It is a good step forward for the next generation of students and young researchers," she says, although there was no extra funding for postdoctoral fellowships.

The budget also proposes expanding parental leave for student researchers, providing Can $\$ 37.4$ million over five years to extend coverage from 6 to 12 months for students funded by any of the three main research agencies.

\section{WHO panel enters CRISPR-baby debate}

\section{World Health Organization advisory committee calls for registry of studies that involve editing the human genome.}

\section{BY SARA REARDON}

$\mathrm{T}$ The World Health Organization (WHO) should create a global registry of studies that involve editing the human genome, and research funders and publishers should require scientists to participate in it, a group advising the WHO said on 19 March.

The WHO created the panel in December after a scientist in China used the gene-editing tool CRISPR to modify the genomes of twin baby girls. In its statement, the panel also opposed the clinical application of research that alters the genome of human eggs, sperm or embryos - called the germ line - in ways that can be passed down to future generations.

"The committee agrees it is irresponsible at this time for anyone to proceed with clinical applications of human germline genome editing," says Margaret Hamburg, the panel's co-chair and foreign secretary of the US National Academy of Medicine.

But she emphasizes that the WHO panel is not calling for a permanent moratorium on such research. "We are trying to look at the broader picture and a framework for responsible stewardship," says Hamburg, a former commissioner of the US Food and Drug Administration. "I don't think a vague moratorium is the answer for what needs to be done."

The advisory panel, which is developing an international framework to govern the use of gene-editing technologies in people, will issue final recommendations to the WHO's directorgeneral in 18 months.

Hamburg did not offer hints as to whether the WHO is considering ways to create a binding international agreement governing gene editing, or to ensure that governments enforce existing laws. The advisory committee's charge includes understanding the differences between how countries regulate such research, she says: "It's a daunting task, but it's the beginning of a process, and we don't really know all 